\title{
Arduino-Based Milk Quality Monitoring System
}

\section{Sumitra Goswami ${ }^{1 *}$ and Ashok Dangi ${ }^{2}$}

${ }^{1}$ Engineering \& Technology Center for Animal Sciences, Rajasthan University of Veterinary and Animal Sciences, Bikaner, Rajasthan, India

${ }^{2}$ Principal Investigator, Engineering \& Technology Center for Animal Sciences, Rajasthan University of Veterinary and Animal Sciences, Bikaner, Rajasthan, India

"Corresponding author: summy_15@yahoo.co.in (ORCID ID: 0000-0001-6100-7853)

Paper No. 906

Received: 18-03-2021

Revised: 29-05-2021

Accepted: 20-06-2021

\begin{abstract}
The current generation has seen a significant rise in milk demand, which has increased the number of milk centers in various regions. Milk is the most important source of nutrition for children, pregnant women, and adults. Milk of the highest quality is dense and free of contaminants. A few adulterants are added to milk to sustain milk income and increase yield. Since farmers supply so much of the milk, there's a fair chance they'll get the information wrong if they don't know what they're doing. The consistency of milk can be harmed by these adulterants. Adulteration of milk has been a major social problem in recent years. Consumption of tainted milk can result in serious health problems. Milk adulteration must be detected, and milk consistency must be ensured. Various types of sensors, such as $\mathrm{pH}$ sensors, gas sensors, and temperature sensors, may be used to detect milk adulteration. This implementation is designed to make the process more apparent to all people who deposit milk. The Arduino controller is used in this framework. The entire milk analyzer system is regulated by this Arduino. Controllers are connected to a variety of sensors. This is an easy-to-use method.
\end{abstract}

\section{HIGHLIGHTS}

(- Arduino-Uno used in this system which provide a faster and reliable result than previously implemented milk analyzer system.

(0 Four different types of milk samples from different dairies are used in this milk quality analysis system.

(- Study indicated that this system is more efficient than the previous study. This system is user-friendly and easy to use.

\section{Keywords: Arduino, FAT measurement, gas sensor, LDR, LED, pH Sensor, temperature sensor}

Humans consume milk and milk products as their main sources of nutrition. In general, dairy products are high in carbohydrates, sugar, protein, vitamins, enzymes, and minerals. However, the quality of nutrients can differ as per the breed of cow, feed, season, lactation stage, and a variety of other factors. The term "adulteration" refers to the addition of other substances in milk to increase the amount of raw milk available. Besides, contamination of milk may occur during unsanitary processing, packaging, and distribution. The most popular adulterant used for milk is water, which raises the quantity of milk while lowering the quality. The consistency of milk is also affected by various environmental factors such as temperature, humidity, and darkness.
Refrigeration and vacuum storage are commonly used to control such factors.

Despite India being the largest milk producer across the world, milk consistency and hygiene are major concerns here. To avoid adulteration milk needs to be analyzed for consistency. It is common knowledge that adulterated milk is sold and consumed in India, which includes adulterants such as detergent, water, urea, starch, and other adulterants. Such adulterants lower the nutritional

How to cite this article: Goswami, S. and Dangi, A. 2021. ArduinoBased Milk Quality Monitoring System. IJAEB, 14(2): 245-249.

Source of Support: None; Conflict of Interest: None

(क) 
value of milk along with lowering its consistency. As the relation between the milk constituents is secure, it can be used to assess the level of adulteration in the milk.

As per a national survey conducted across the country, approximately $68.4 \%$ of the milk samples tested did not fulfill the set milk requirement. Thus, it is imperative to monitor milk quality monitored at the dairy farm by the farmer using a clear, accurate, hand-held adulteration detection device pr computer that can detect pH, FAT, odor, and other adulterants in milk.

\section{MATERIALS AND METHODS}

The Arduino-based milk quality and quantity estimation is presented in this study. Customers will use their cell phones to access milk parameter data in this proposed framework. Using an Android smartphone application such as a serial Bluetooth terminal, data can be saved in their mobile memory as a Milk Log. The real-time clock module records real-time milk parameters such as $\mathrm{pH}$, temperature, salinity, and other milk adulteration.

The amount and types of adulterants added to milk are detected by this method, which analyses the milk content. Electronic devices interfaced with different types of sensors are used to detect adulterants.

The $\mathrm{pH}$ level of milk, which is determined by a $\mathrm{pH}$ sensor, is primarily used to determine the consistency of milk.

The odor of milk is detected using a gas sensor. When milk is processed for a prolonged period, microbial activity occurs, altering the scent of the milk, which can be detected using a gas sensor.

\section{Main Components of the System}

The key components of this proposed Arduino Uno system are as follows:

The UNO version is included in this proposed scheme. A microcontroller is the Arduino Uno. It's an open-source electronics platform board that's a hybrid of hardware and software. It can be directly pre-programmed via USB.

It is based on the ATmega328P microcontroller. Digital I/P and O/P pins, Analog I/P pins, $16 \mathrm{MHz}$ ceramic resonators, USB link, a power jack, and a reset button are all included. It's simple to connect to other electronics modules and sensors. It has a 5 volt DC operating voltage. It is a low-cost microcontroller board that regulates the entire device and provides quicker and more reliable results.

Power Supply Module: The Arduino controller needs a 5-volt dc power supply, which is provided by this power supply module. A rectifier circuit with a step-down transformer is present.

pH Sensor: A pH sensor tests the concentration of hydrogen ions in water or liquid. The $\mathrm{pH}$ scale is a numerical scale that is used to assess the acidity or baseness of a substance.

$$
\mathrm{pH}=-\log \left[\mathrm{H}^{+}\right]
$$

According to their parameters, each liquid has its $\mathrm{pH}$. Pure milk has a $\mathrm{pH}$ range of 6.7 to 6.9 . It depends on the breed of cattle, their lactation period, and their feed. The $\mathrm{pH}$ of milk can change over time or when it has been adulterated. $\mathrm{A} \mathrm{pH}$ sensor was used to determine the $\mathrm{pH}$ of the milk.

Abnormal milk is classified as milk that falls outside of these $\mathrm{pH}$ ranges. The ingestion of this abnormal milk results in several health problems.

Temperature Sensor: A thermometer is used to determine the temperature. Milk has its own set of temperature requirements. That temperature must be maintained during milk storage for an extended period. Milk is typically healthy at temperatures between 35 and 40 degrees Fahrenheit. When some other substance or water is applied to milk, the temperature of the milk is altered from its natural range. Bacteria from when milk is heated above or below its normal temperature level, making it unfit for consumption. The temperature of the milk is controlled using a temperature sensor.

Gas Sensor: New milk has a different odor than adulterated milk. When milk is stored for a long time with the aid of any external contamination and the adulteration and toxicity levels are high, toxic gases are produced. This preserved milk produces gas, which emits a foul odor. This milk can cause several health problems. It is not appropriate for human consumption. Gas sensors or Air Quality Sensors are used to identify poisonous gases in the form of foul odors (MQ135). As a gas sensor, the MQ135 is used. The sensitive material in this sensor 
is $\mathrm{SnO}_{2}$. This substance has low conductivity in clean air, but as the gas content increases, so does the conductivity of this sensitive material. This sensor is extremely sensitive to ammonia, sulfide, smoke, and other hazardous gases. It's a low-cost gas detector. This sensor can also be used as a domestic air pollution detector, as well as a portable and commercial air pollution detector.

LDR (Light Dependent Register): LDR stands for Low-Density Re (Light Dependent Register). It has a variable register that changes depending on the amount of light. When the light intensity is low, LDR resistance increases, and when light intensity is high, LDR resistance decreases. LDR resistance is inversely proportional to light intensity. LDR is suitable for use in Automatic Security Lights.

LCD Display: A liquid crystal display (LCD) is an optical system with a flat-screen. The LCD monitor is used to show the various milk parameters as well as the system's performance.

Bluetooth Module: The Arduino Controller is connected to the Bluetooth module. This system's real-time data is accessed through Bluetooth. Customers and milk depositors can use their own mobile devices to access it, and they can also store data logs on their own mobile devices for later use using an Android device.

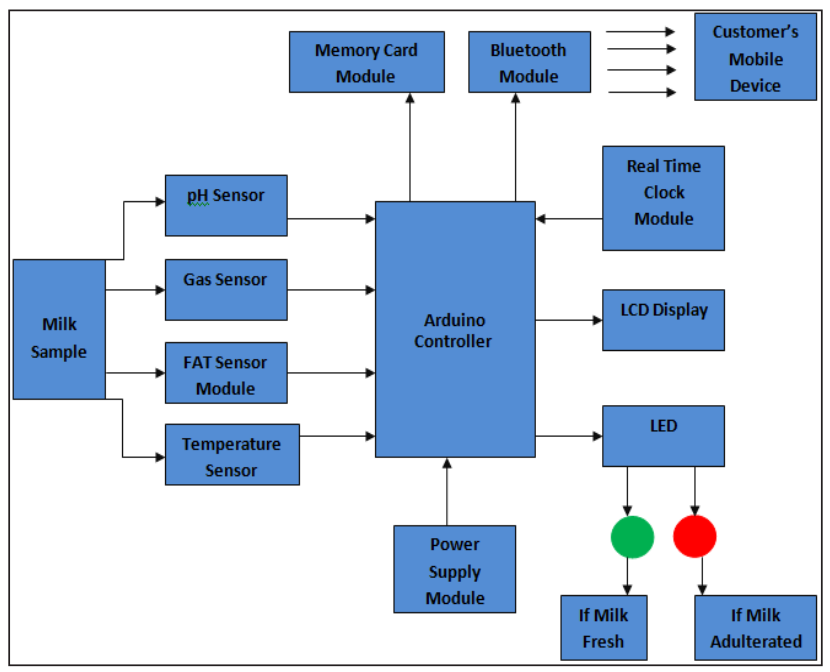

Fig. 1: Block Diagram of Proposed System

\section{Working}

This device can be set up in a nearby dairy or milk vendor where farmers can drop off their milk. As a primary milk analyzer, this device can be used.
When this unit is properly mounted and turned on with a 5-volt dc supply through the power supply module, it is ready to use. It begins by reading data from the various sensors connected to the Arduino Controller. The $\mathrm{pH}$ of a milk sample is detected by a $\mathrm{pH}$ sensor. The $\mathrm{pH}$ of milk should be between 6.5 and 6.8. This gas sensor can detect microbial activity in milk or quantify toxic gas emissions from a milk sample. The temperature of the milk is determined by a temperature sensor, and the FAT is measured using the light scattering principle. LEDs are used to emit light beams, and LDRs are used to calculate the scattering of such beams. When a milk sample test tube is mounted between LED and LDR for this FAT measurement module, a light beam (emitted by LED) passes through the test tube of sample milk. When a light beam passes through a milk sample, the milk tends to disperse it. The milk sample collected by Light Dependent Register scatters light, and this light scatters from the milk sample collected by Light Dependent Register. The resistance of the LDR varies as the light scattered from the milk sample changes, and the measured data is sent to the controller board. If the milk has a higher fat content. The sample scatters a large amount of light. The amount of light scattered from Milk has an inverse relationship with the shift in LDR resistance. The proposed system's block diagram and working model are shown in Fig. 1 and 2, respectively.

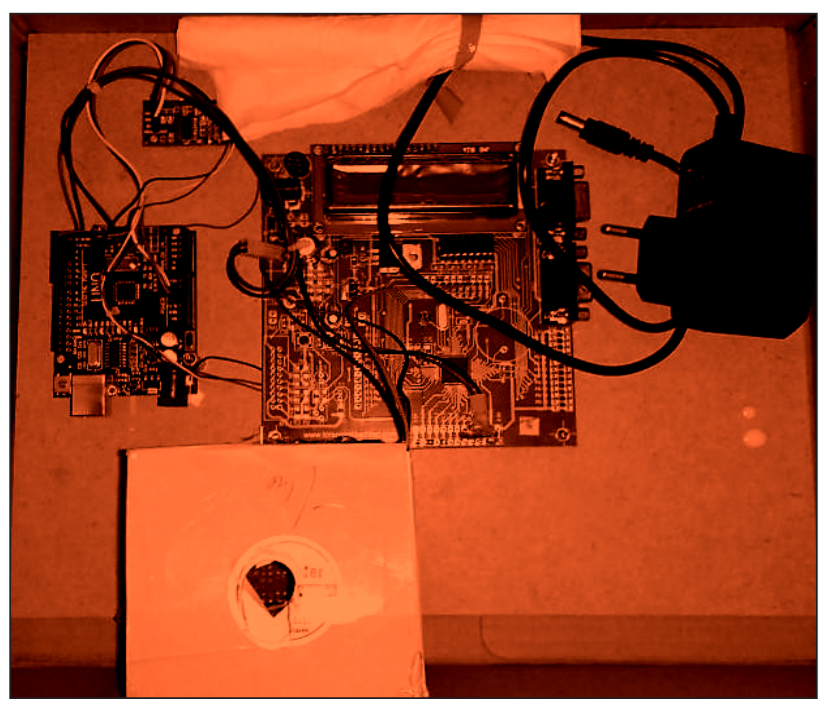

Fig. 2: Working model of Proposed System

The range of Fat content in different cattle 3.0 to 4.0 percent fat in cow milk

7-8 percent for Buffalo 
Arduino is in charge of the whole system's operation. This system is pre-calibrated with criteria that have known values for various milk parameters. When all parameters are within normal range, the Green LED blinks. When all parameters are within normal range, the Green LED blinks. It means that the milk sample is fresh or pure milk that is free of toxins.

The RED LED blinks if the sample parameters are below or above the standard values. It means that the milk sample has been tampered with or that it is poisonous or unfit for consumption. The sample data can be accessed by a mobile device via the Bluetooth module, which is attached to this Controller. For each sample, the Real-Time Clock module produces a real date and time log. A memory card is used to store the data file. And, thanks to Bluetooth, each customer can save these $\log$ data to their mobile device. Table 1 shows a milk analyzer observation table.

\section{RESULTS AND DISCUSSION}

We have analyzed four milk samples using this milk analyzing system. We have analyzed 5 factors of various milk samples. Pure Milk, water in milk, salt in milk, and soap adulterants in milk. Analysis of these milk samples is showing in Table 1. We have discussed various previous research work of milk quality analysis.

A microcontroller-based system for data monitoring and milk quality analysis is built (Khera et al. 2019). Important milk parameters such as $\mathrm{pH}, \mathrm{CLR}, \mathrm{FAT}$, and SNF are controlled using this method. The butyrometer is used to measure the fat content of milk. CLR is measured using a lactometer. The SNF value is calculated using the FAT percentage and CLR value. The paper outlined the design and manufacturing process for a low-cost sensing technique based on a radio-frequency excitation electromagnetic planar sensor. Online quality control can be achieved easily thanks to computerassisted computing (Mukhopadhyay et al. 2005). An IoT-based framework is created (Rajakumar and et al. 2018). The microbial behavior in this system is determined by a gas sensor. The salinity of the milk is calculated by a salinity sensor, and the level of the milk is measured by a level sensor in this device. This system is also RFID-based. Customers have an RFID card that allows them to keep track of their milk dairies. This device tests milk weight, fat, and
CLR. This system is both fast and precise. They created a Raspberry Pi3-based framework for this research (Thanedar et al. 2018). They used a webbased platform to replace the desktop application. They devised a method of communicating wirelessly between the mil automation system and the server. They used IoT and data mining to build a milk automation machine. This system reduces overall costs while increasing productivity. This study is focused on the principle of spectroscopy (Sujatha et al. 2019). They created an automated fat measurement device as part of this study. This system is based on embedded technology. For all milk depositors, this device used RFID techniques for unique identification. This can be used to store all information about all milk depositors for future use. They used an Arduino Microcontroller to create a Milkotester for measuring FAT and CLR in milk (Abhishek $\mathrm{M}$ et al. 2017). They devised a low-cost method for determining mil parameters such as SNF (Solid but not FAT), FAT, and CLR. They built a smart milk quality detection system in this study (Mahale et al. 2018). Cantered on an Arduino controller, this is a low-cost and effective milk parameter measurement device. The $\mathrm{pH}$, FAT, and SNF of the milk were all determined by this method (Solid but not Fat). To capture milk parameters, the researcher created an Arduino-based device (Bhamre et al. 2016). This device detects milk parameters such as volume, $\mathrm{pH}, \mathrm{CLR}$, and SNF. To measure quantity, $\mathrm{pH}$, and CLR, this device employs an ultrasonic sensor, a $\mathrm{pH}$ sensor, and a lactometer. This device is both inexpensive and reliable at detecting milk adulteration. Many methods of milk testing are explored in this review article. Various types of sensors were used to detect milk parameters. If milk has been processed for a long time, microbial activity can be identified using a gas sensor. For milk parameter analysis, ultrasound techniques are most widely used (Chavan et al. 2019). This system is built on the Internet of Things (IoT) (Internet of Thinking). Sensors are attached to an Intel Galileo Gen II board in this system. The results of the sensor were saved on the cloud by this Intel Galileo Gen II. Every consumer has access to the data that has been saved. To access these details, you must first log in (Abhishek $\mathrm{M}$ et al. 2017). The AVR Microcontroller (Bhade et al. 2019) is used to implement this device. All sensors are integrated with this system to create a compact system. This analyses the quality of milk 
Table 1: Observation table of the Milk Analyzer system

\begin{tabular}{llllll}
\hline Samples & Fat & $\mathbf{p H}$ & Temperature & Odor & Quality \\
\hline Pure milk & $3.2-3.5 \%$ & 6.8 (Normal) & 30.31 & $5 \%$ & High \\
Water + milk & $0.5-2 \%$ & 6.4 (Normal) & 31.56 & $5 \%$ & Normal \\
Milk + salt & $4-5 \%$ & 4.5 (Acidic) & 31.38 & $10 \%$ & Low \\
Milk + soap & $4-5 \%$ & 8.8 (Alkaline) & 32.43 & $11 \%$ & Low \\
\hline
\end{tabular}

using various parameters and displays the results on an LCD screen. These types of milk monitoring systems can help avoid problems in dairies. This system is lightweight and simple to run.

\section{CONCLUSION}

We designed an Arduino-based system to measure milk quality and provide a faster and more reliable result than the previously developed milk quality analyzer system. This machine can be used as a primary milk quality analyzer for all milk depositors in a dairy booth. Alternatively, customers may use Bluetooth to verify quality analyzer data on their mobile devices. The Arduino Controller is attached to the Bluetooth module. The dairy vendor will keep track of the milk analysis data for the entire month. Real-time data of milk parameters calculated by various sensors were also stored using the real-time clock unit. Customers can also verify the milk parameters of the dairy where the system is mounted. This system is simple to use and provides reliable information. This is a cost-effective and dependable method. We will use the Data Base Management System to expand this system in the future. All information about milk depositors and customers is stored in SQL. This information is then used for billing every month.

\section{REFERENCES}

Aware, A.M. and Belorkar, U. 2017 Design of Milkotester for Fat and CLR Measurement using Arduino Microcontroller. I. Adv. Res. J. Sci. Engi. Tech., 4(5): 14-17.

Aware, A.M. and Belorkar, U. 2017. Design of Milk Analysis System for Dairy Farmers Using Embedded System. Int. J. Innov. Re. Ele. Electro. Instrumen. Control Engg., 5(5) : 11-16.

Unnikrishnan, A., Ravindran, A., Sreedhar, A. and Kuruvila, S.V. 2015. Electro-Milktestera Novel Method for Analysis of Milk Quality. Int. J. Innov. Res. Sci. Eng. Technol., 2(04): 103-108.

Borecki, M., Szmidt, M., Paw, M., K, Beb, M., Niemiec, T. and Wrzosek, P. 2017. "A method for testing the quality of milk using optical capillaries. Photonics Letters of Poland, 1(2): 37-39.
Brennan, D., Alderman, D., Sattler, L., Connorb, B. and Mathunaa, C. 2003. Issues in development of NIR micro spectrometer system for on-line process monitoring of milk product. Measurement, 33(1): 67-74.

Brown, J.V., Ranjith. H.M.P. and Prentice, G.A. 2018. Comparative shelf-lives of skimmed, semi-skimmed and whole milks. Int. J. D. Tech., 37(4): 2-5.

Chavan, R. and Patil, U.V. 2019. Comprehensive Assessment of Various Milk Parameters Using Embedded and IoT Based Systems. Int. J. Sci. Adv. Res. Technol., 5(7): 42-46.

Bhade, Dobariya, S.J., Landge, S.S., Babhale, P.D. and Atmande, V.M. 2019. Implementation of IoT based Milk Quality Analyzer using AVR Microcontroller. J. Emerg. Technol. Innov. Res., 6(5): 54-61.

Mahale, S., Deshmukh, S., Nakhate A., Ambure A. and Chavan K. 2018. Smart Milk Quality Detection System. Int. J. Res. Engi. Applic. Manag. ICRTET180 : 918-919.

M Sujatha, P. Nagarjuna, A. Bala Sai Ram, A. Hemanth Venkata Sai, K. Tarun, Sk Hasane Ahammad. 2019. Visible Spectroscopy Analysis of Fat Content in Milk using Lab View. Int. J. R. Tech. Eng., 7(5S4): 746-750.

Khera, N., Kumar, A., Fajr, F. and Khajwal, T.N. 2019. Microcontroller Based Parametric Data Monitoring and Quality Analysis of Milk. 2019 International Conference on Issues and Challenges in Intelligent Computing Techniques, Ghaziabad, India. 1-3: http:///dx.doi.org/10.1109/ ICICT46931.2019.8977704

Rajakumar, G., D.A. Kumar, D.T. Samuel, E. Muthu and Kumaran. 2018. IoT Based Milk Monitoring System for Detection of Milk Adulteration. Int. J. P A. Math., 118(6): 21-32.

Mukhopadhyay, S.C., Gooneratne, C.P., Demidenko, S. and Gupta, G.S. 2005. Low-Cost Sensing System for Dairy Products Quality Monitoring. 2005 IEEE Instrumentation and Measurement Technology Conference Proceedings. 244249: http://dx.doi.org/10.1109/IMTC.2005.1604109

Thanedar, P., Pol, S., Shinde, A., Mayekar, A. and Shinde, S. 2018. Enhanced Automation of Milk Analyzer Using Internet of Things (IoT) and Data Mining. Int. J. I. I. Res. Dev., 03(1): 12-17.

Yadav, S.N., Kulkarni, V.A. and Gholap, S.G. 2012. Design of Milk embedded system for dairy farmers. Int. J. Elec. C. Engi. Tech., 3(2): 497-500.

Bhamre, Y.R., Matsagar, M.B. and Bighavkar, C.G. 2016. Quantitive and Qualitative Analysis of Milk Parameters using Arduino Controller. Int. J. A. Res. Comp. Comm. Eng., 5(8) : 46-49. 
